\title{
HYPERSPECTRAL ANALYSIS OF CLAY MINERALS
}

\author{
Janaki Rama Suresh $\mathrm{G}^{\mathrm{a} *}$, Sreenivas $\mathrm{K}^{\mathrm{a}}$, Sivasamy $\mathrm{R}^{\mathrm{b}}$ \\ ${ }^{a}$ Soil \& Land Resources Assessment Division, National Remote Sensing Centre, Hyderabad \\ ${ }^{\mathrm{b}}$ Dept. of Remote Sensing and Geographic Information System, Tamil Nadu Agricultural University, Coimbatore
}

KEY WORDS: Clay minerals, X Ray Diffraction, Hyperspectral, DISPEC, Spectral Angle Mapper

\begin{abstract}
:
A study was carried out by collecting soil samples from parts of Gwalior and Shivpuri district, Madhya Pradesh in order to assess the dominant clay mineral of these soils using hyperspectral data, as 0.4 to $2.5 \mu \mathrm{m}$ spectral range provides abundant and unique information about many important earth-surface minerals. Understanding the spectral response along with the soil chemical properties can provide important clues for retrieval of mineralogical soil properties. The soil samples were collected based on stratified random sampling approach and dominant clay minerals were identified through XRD analysis. The absorption feature parameters like depth, width, area and asymmetry of the absorption peaks were derived from spectral profile of soil samples through DISPEC tool. The derived absorption feature parameters were used as inputs for modelling the dominant soil clay mineral present in the unknown samples using Random forest approach which resulted in kappa accuracy of 0.795 . Besides, an attempt was made to classify the Hyperion data using Spectral Angle Mapper (SAM) algorithm with an overall accuracy of 68.43\%. Results showed that kaolinite was the dominant mineral present in the soils followed by montmorillonite in the study area.
\end{abstract}

\section{INTRODUCTION}

Soil is a very complex medium consisting of several constituents that affect the spectral reflectance of soil. Based on the chemical and physical composition different soils have specific absorption of reflection at different wavelengths.

Reflectance spectrometry gained importance due to the potential in rapid identification of constituent minerals in soils (Clark, King, Klejwa, \& Swayze, 1990; Hunt, 1977; Hunt \& Salisbury, 1970). Hyperspectral remote sensing, or imaging spectroscopy, consists of acquiring images in many $(>100)$ narrow, contiguous spectral bands (Goetz, Vane, Solomon, \& Rock, 1985), thus providing a continuous spectrum for each pixel. Hyperspectral images enable spectral identification of minerals, rocks, or soils at the surface, with laboratory-like reflectance spectroscopy at the remote sensing scale (Sabine Chabrillat et al, 2002). Hence, hyperspectral sensors provide a vastly improved ability to classify the objects in the scene based on their spectral properties (Goetz et al., 1985).

Most of the clay minerals show distinctive spectral reflectance patterns at visible wavelengths and especially at reflected IR wavelengths (Hunt, 1980). In the SWIR, soil spectra display more features than those observed in shorter wavelengths but are still dominated by water content, litter, and minerals (Gausman et al., 1975b; Henderson et al., 1992; Daughtry, 2001).

The 0.4 to $2.5 \mu \mathrm{m}$ spectral range provides abundant information about many important Earth-surface minerals (Clark et al., 2001). In particular, the 2.0 to $2.5 \mu \mathrm{m}$ spectral range covers spectral features of hydroxyl-bearing minerals, sulfates, and carbonates common to many geologic units and hydrothermal alteration assemblages. Imaging Spectrometers or hyperspectral sensors provide the unique combination of both spatially contiguous spectra and spectrally contiguous images of the Earth's surface that allows spatial mapping of these minerals
(Goetz et al., 1985). Airborne hyperspectral data have been available to researchers since the early 1980s and their use for mineral mapping is well established (Goetz et al., 1985; Kruse and Lefkoff, 1993; Boardman and Kruse, 1994; Boardman et al., 1995; Kruse, et al., 1999).

Keeping the above mentioned views, present study was carried out to analyze spectral characteristics of dominant clay minerals in soils.

\section{STUDY AREA}

The study was conducted in parts of Gwalior and Shivpuri districts of Madhya Pradesh. The area has a humid sub-tropical climate with average annual rainfall of $916 \mathrm{~mm}$. The study area is generally covered with sandy clay soil derived from the weathering of Bundelkhand granites and the Vindhyan formations. Certain parts of the area are covered by the black cotton soils derived by the weathering of the Deccan trap formation and the lateritic soil. Alluvium is found all along the major and minor rivers.

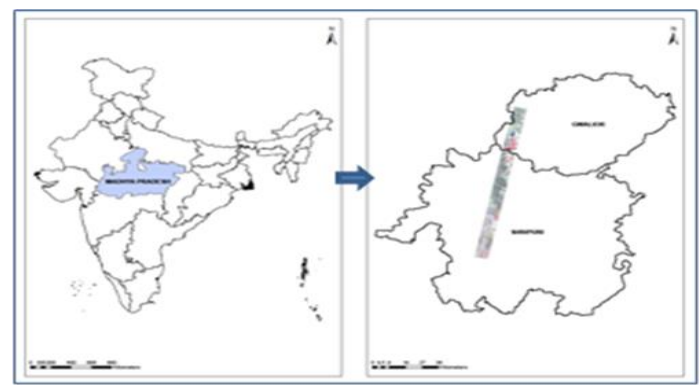

Figure 1. Location map of the study area

\footnotetext{
* Corresponding author: suresh_gunnam@nrsc.gov.in, janakirama17@gmail.com.
} 


\section{MATERIALS AND METHODS}

\subsection{Satellite data used:}

For sampling plan preparation and hyperspectral classification of soil mineralogy, Hyperion data (L1T product with 242 bands at $10 \mathrm{~nm}$ band width) acquired on $14^{\text {th }}$ April, 2011 was used. The data was downloaded from the U.S Geological Survey website.

\subsection{Collection and preparation of soil samples}

Using the pre-acquired Hyperion data and existing soil maps, sampling sites were determined. Field data has been collected at various distinct soil locations and soil samples were collected for XRD analysis, spectral analysis and analysis of other chemical properties. The soil samples were treated with the glacial acetic acid to remove the carbonates and $\mathrm{H}_{2} \mathrm{O}_{2}$ to remove the organic matter. The silt and clay in the suspension were separated by decantation or by centrifugation using sodium hexametaphosphate, a dispersant or deflocculant. The dried samples are ground with mortar and pestle so that the particles are finer than $0.062 \mathrm{~mm}$ to avoid mineral fractionation.

\subsection{Clay mineral extraction and identification by XRD}

$\mathrm{X}$-ray powder diffraction, which is the most common technique to study the characteristics of crystalline structure and to determine the mineralogy of fine sediments like clays, was used in the present study. The procedure mentioned in "A laboratory manual for X ray diffraction" by U. S. Geological Survey was followed for the extraction and identification of clay minerals. The samples were smeared on the surface of the glass slide and sufficient amount of acetone was added to wet the sample and subsequently exposed to ethylene glycol to expand swelling clays and placed in dessicator at $60-70^{\circ} \mathrm{C}$ and heat treatments at $400^{\circ} \mathrm{C}$ and $550^{\circ} \mathrm{C}$. The samples are glycolated for atleast $4 \mathrm{hrs}$ by vapour glycolation technique using $\mathrm{LiCl}$. The mount is $\mathrm{x}$ rayed between angles of $2 \& 70$ degrees two theta using copper $\mathrm{K}$ alpha radiation at scanning rate of 2 degrees per minute. Using the Bragg equation degrees two theta was converted to interplanar spacing.

$$
\mathrm{D}=\lambda_{\mathrm{o}} / 2 * \sin (0.5 \times 2 \theta \times \mathrm{R})
$$

Where,

$\mathrm{D}=$ Inter lattice spacing in angstroms

$\lambda_{\mathrm{o}}=$ Wavelength of the characteristic X-rays

$\theta=X$-ray incidence angle (Bragg angle)

$\mathrm{R}=$ conversion factor used to change degrees to radians

( 0.0174532925199433).

\subsection{Laboratory spectral observations}

Spectral reflectance of the soil samples were collected over the 350-2500 nm wavelength range with a Field Spec®Pro Spectrometer (Analytical Spectral Device-ASD).The radiometer consists of one silicon photodiode array and two fast scanning thermoelectrically (TE) cooled spectrometers with a spectral resolution of $10 \mathrm{~nm}$. The instrument was operated with $5^{\circ}$ full field-of-view (FFOV) fore optics. A laptop interface with the instrument allows real time viewing of the spectrum recorded. A white Spectralon panel provided the absolute reflectance factor both for field and laboratory measurements.

\subsection{Spectral Reflectance analysis}

The reflectance spectra of the soil samples, especially the absorption features of the spectra were analysed using the DISPEC (Version 3.2), an IDL program developed by Harald Vander Werff (www.itc.nl/personal/vdwerff/software.html). The programme characterizes the shape and wavelength position of strongest absorption features in the reflectance spectra for detailed spectral analysis. The absorption features were calculated by the programme based on position or centre of absorption band, depth, width, area and asymmetry of the continuum removed spectra.

\subsection{Modeling approach}

The absorption feature parameters that were obtained using the DISPEC tool were used as input parameters for modeling the dominant soil clay mineral in the soil samples using the random forest approach and the unknown samples were classified. The random forests, an extended classification and regression tree (CART) model constructs multiple regression trees and adopts ensemble approach for prediction of output value. The random forests as adopted in R through Rattle package (Williams, 2009) was used in this study.

\subsection{Classification by Spectral Angle Mapper}

The Hyperion data has been subjected to radiance conversion, smile correction and atmospheric correction (FLAASH). The training sets were provided based on field location information and based on XRD data dominant mineralogy class has been assigned to training set. The corrected hyperion imagery was subjected to classification using spectral angle mapper (SAM) using the above training sets. About $15 \%$ of samples were kept aside for post-classification verification. The SAM method developed by Kruse et al. (1993) is a classification approach based on the similarity between two spectra. The measurement of the angular difference permits the allocation of each spectrum of the image to a given class. The method determines the similarity between the reference spectrum and the image spectrum by the calculation of the angle. The spectral angle is calculated from the following equation:

$$
\theta=\cos ^{-1}\left(\frac{\sum_{\mathrm{i}=1}^{n} t_{\mathrm{i}} r_{\mathrm{i}}}{\sqrt{\sum_{\mathrm{i}=1}^{n} t_{\mathrm{i}}^{2} \sum_{\mathrm{i}=1}^{n} r_{\mathrm{i}}^{2}}}\right)
$$

Where $r=$ reference spectrum vector (prototype) and $t=$ test spectrum vector (pixel).

\section{RESULTS AND DISCUSSION}

\subsection{Identification of dominant clay minerals}

Mineralogy of the soil samples has been assessed through XRD analysis. The dominant clay minerals in the soil samples were identified by dominant peak producing $d$ spacings. The soil samples were subsequently grouped based on presence of dominant minerals in soil. On an average the dominant mineral present was as follows kaolinite>montmorilonite>illite. Results indicated that the kaolinite abundant soils showed dominant 
peaks mostly at $12.3,24.8$ and $37.7 \AA \mathrm{d}$ spacing where as montmorilonite abundant soils at 4.9, 9.82 and $14.7 \AA \mathrm{d}$ spacing in the study area (Table. 1).

\begin{tabular}{|l|l|}
\hline Clay Mineral & Peak producing d spacing in angstroms \\
\hline Kaolinite & $12.3,24.8,37.7,51.0,65.1$ \\
\hline \multirow{2}{*}{ Vermiculite } & $6.13,12.2,18.4,24.7,31.0,37.4,43.9,50.6,57$. \\
& $56,64.6$ \\
\hline Illite & $8.84,17.7,26.7,35.8,45.3,55.0,65.2$ \\
\hline Montomorillon & $4.9,9.82,14.7,19.7,24.7,29.7,34.8,40.04,45$. \\
ite & $3,50.6$ \\
\hline Goethite & $4.18,21.2,43.2,67.1$ \\
\hline
\end{tabular}

Table. 1 Dominant peak producing d spacings $(\AA)$ in the clay minerals.

\subsection{Spectral analysis of absorption features}

The hyperspectral absorption feature parameters i.e, depth, width, area and asymmetry of the absorption peaks at 1400 $1450 \mathrm{~nm}, 1900-1920 \mathrm{~nm}$ and $2200-2210 \mathrm{~nm}$ were derived from spectral profile of soil samples using the DISPEC tool. It was observed that, Kaolinite, montmorillonite and Illite are the clay minerals which were common in these soil samples. The strong absorption band near $1.4 \mu \mathrm{m}$, along with the weak $1.9 \mu \mathrm{m}$ band in kaolinite, are due to hydroxide ions, while the stronger 1.9 $\mu \mathrm{m}$ band in montmorillonite is caused by bound water molecules in this hydrous clay. The SWIR spectra of illite showed two diagnostic absorption peaks at the $1.4 \mu \mathrm{m}$ and 2.2 $\mu \mathrm{m} \mathrm{nm}$ regions. The $1.4 \mu \mathrm{m}$ peak is derived from the $\mathrm{OH}-$ overtone stretching vibration, and the $2.2 \mu \mathrm{m}$ absorption is related to the $\mathrm{Al}-\mathrm{OH}$ bending combined with $\mathrm{OH}$ stretching (Hauff et al. 1991, Masinter \& Lyon 1991). An additional peak at the $1.9 \mu \mathrm{m}$ region in some illite separates is related to adsorbed water.

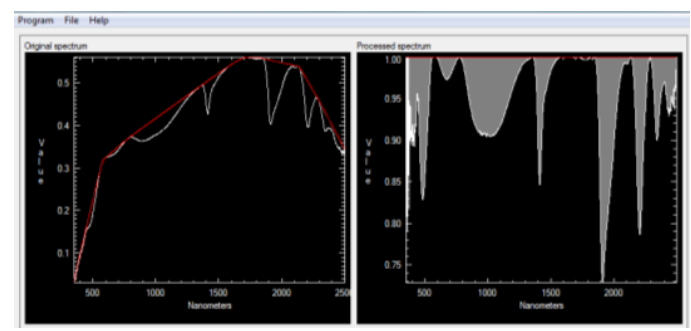

Figure 2. The original and continuum removed spectra of a Kaolinite dominant soil sample.

It should be emphasized that infrared spectra are influenced mainly by short-range order and are relatively insensitive to long-range order in minerals, whereas XRD patterns are more sensitive to long-range order (e.g., Gaite et al. 1997). Therefore, information about the clay mineral structure derived from infrared spectroscopy is not expected to be identical to that from XRD.

These derived absorption feature parameters were used as input variables for modeling the dominant soil mineralogy class using random forests approach. Of these variables a maximum variance of $31 \%$ was explained by width of the absorption indicating the importance of the variable in the prediction. Using this model, the unknown samples were classified which has resulted in a kappa accuracy of 0.795 . The error matrix indicating the number of samples classified in each mineralogy class in accordance with the ground truth and XRD analysis is presented in the table 2 .

\begin{tabular}{|c|c|c|c|c|c|}
\hline & $\mathbf{K}$ & $\mathbf{M}$ & $\mathbf{I}$ & $\mathbf{G}$ & $\mathbf{V}$ \\
\hline $\mathbf{K}$ & 22 & 0 & 0 & 0 & 0 \\
\hline $\mathbf{M}$ & 3 & 18 & 1 & 0 & 0 \\
\hline $\mathbf{I}$ & 0 & 1 & 9 & 0 & 1 \\
\hline $\mathbf{G}$ & 0 & 1 & 0 & 5 & 2 \\
\hline $\mathbf{V}$ & 0 & 0 & 1 & 1 & 6 \\
\hline
\end{tabular}

Table 2. Error matrix of the random forest based classification (K=Kaolinite, $\mathrm{M}=$ Montomorillonite, $\mathrm{I}=\mathrm{Illite}, \mathrm{G}=$ Goethite, $\mathrm{V}=$ Vermiculite)

\subsection{Image Classification}

An effort was made to classify the Hyperion data using Spectral Angular Mapper (SAM) algorithm. The output is provided as figure 3. The algorithm was trained based on the field observations in combination with XRD analysis and the image was classified using SAM. It was observed that Kaolinite is the dominant mineral of the study area followed by Montmorillonite. The accuracy was assessed by studying the error matrix and the overall accuracy of the classification was found to be $68.43 \%$. In the study area the uplands are mainly with non-expanding clay minerals, while lowlands (bottom portion of the image) are dominated by expanding clay minerals. The predominance of montomorillonite in lowlands indicates a high base status of weathering environment (Gawande etal 1974).

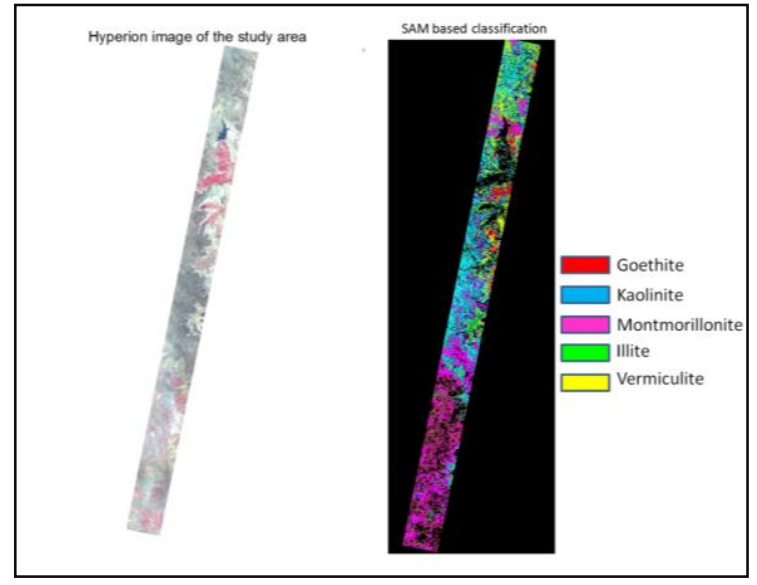

Figure 3. Classified Hyperion image using SAM algorithm

\section{CONCLUSIONS}

The study explored the possibility of using the hyperspectral field as well as satellite based observations for deriving dominant clay minerals. The results from modelling dominant clay minerals by Random forests and mapping of hyperion data using SAM algorithm indicated the dominance of Kaolinite clay mineral followed by montomorillonite in the study area.

It was also found that the spectral absorption features found to be useful parameters to assess the dominant clay mineral of soils from laboratory spectra of soil clays. However due to mixed nature of clay minerals in natural soil samples in the 
present study determination of only dominant clay mineral is explored. Attempts are being made to find the composition of clay mixtures through linear decomposition techniques.

\section{ACKNOWLEDGEMENTS}

We sincerely thank National Remote sensing Centre, ISRO for providing the financial support for the study. We owe our thanks to Dr. V.K. Dadhwal, Director, NRSC for his critical review and suggestions. All the authors would like to express their sincere gratitude to Bharathiar University - DRDO Centre for Life Sciences and Tamil Nadu Agricultural University, Coimbatore for extending necessary support in successful execution of this study.

\section{REFERENCES}

Boardman J. W., and Kruse, F. A., 1994, Automated spectral analysis: A geologic example using AVIRIS data, north Grapevine Mountains, Nevada: in Proceedings, Tenth Thematic Conference on Geologic Remote Sensing, Environmental Research Institute of Michigan, Ann Arbor, MI, p. I-407 - I418.

Boardman, J. W., Kruse, F. A., and Green, R. O., 1995, Mapping target signatures via partial unmixing of AVIRIS data: in Summaries, Fifth JPL Airborne Earth Science Workshop, JPL Publication 95-1, v. 1, p. 23-26

Clark, R. N., King, T. V. V., Klejwa, M. and Swayze, G. A., 1990. High spectral resolution reflectance spectroscopy of minerals. Journal of Geophysical Research, 95(B8), 12:65312:680.

Clarke, T.R., M.S. Moran., E.M. Barnes., P.J. Pinter, Jr., and J. Qi., 2001. Planar domain indices: A method for measuring a quality of a single component in two-component pixels, Proceedings IEEE International Geoscience and Remote Sensing Symposium, 09-13 July, Sydney, Australia.

Daughtry, C.S.T., 2001. Discriminating crop residues from soil by shortwave infrared reflectance, Agronomy Journal, 93(1):125-131.

Gaite, J.M., Ermakoff, P., Allard, T. and Muller, J.P., 1997. Paramagnetic $\mathrm{Fe} 3+$ : a sensitive probe for disorder in the kaolinite. Clays and Clay Minerals 45, 496-505.

Gausman, H.W., A.H. Gerbermann, and C.L. Wiegand, 1975a. Use of ERTS-1 data to detect chlorotic grain-sorghum, Photogrammetric Engineering \& Remote Sensing, 41(2):177179.

Gawande S.P., Biswas T.D. 1974. Report on "Genesis and distribution of clay minerals in catenary soils of Chatisgarh basin of Madhya Pradesh" http://www.new1.dli.ernet.in/data1/upload/insa/INSA_1/20005 b17_192.pdf

Goetz, A. F. H., Vane, G., Solomon, J. E., and Rock, B. N., 1985. Imaging spectroscopy for Earth remote sensing. Science, 228, 1147-1153.
Hauff, P., Kruse, F.A., Madrid, R., Fraser, S., Huntington, J., Jones, M. and Watters, S. 1991. Illite crystallinity - case histories using X-ray diffraction and reflectance spectroscopy to define ore host environments. In Proc. Eighth Thematic Conf. on Geologic Remote Sensing (Denver), 447-458.

Henderson, T.L., M.F. Baumgardner, D.P. Franzmeier, D.E. Stott, and D.C. Coster, 1992. High dimensional reflectance analysis of soil organic-matter, Soil Science Society of America Journal, 56(3):865-872.

Hunt, G. R., \& Salisbury, J. W. 1970. Visible and near-infrared reflectance spectra of minerals and rocks, I: silicate minerals. Modern Geology, 1, 219-228.

Hunt, G. R., 1977. Spectral signatures of particulate minerals in the visible and near-infrared. Geophysics, 42, 501-513.

Hunt, G.R., 1980. Electromagnetic radiation - the communication link in remote sensing. In: Siegal, B.S., Gillespie, A.R._Eds.., Remote Sensing in Geology, Wiley, New York, NY.

Kruse, F. A., and Lefkoff, A. B., 1993, Knowledge-based geologic mapping with imaging spectrometers: Remote Sensing Reviews, Special Issue on NASA Innovative Research Program (IRP) results, v. 8, p. 3 - 28.

Kruse, F. A., Boardman, J. W., and Huntington, J. F., 1999. Fifteen Years of Hyperspectral Data: northern Grapevine Mountains, Nevada: in Proceedings of the 8th JPL Airborne Earth Science Workshop: Jet Propulsion Laboratory Publication, JPL Publication 99-17, p. 247 - 258.

Kruse, F. A., Lefkoff, A. B., and Dietz, J. B., 1993b. Expert System-Based Mineral Mapping in northern Death Valley, California/Nevada using the Airborne Visible/Infrared Imaging Spectrometer (AVIRIS): Remote Sensing of Environment, Special issue on AVIRIS, May-June 1993, v. 44, p. 309 - 336.

Masinter, R.A. and Lyon, R.J.P., 1991. Spectroscopic confirmation of increasing illite ordering with hydrothermal alteration of argillaceous ore in the Gold Bar Mine, Eureka CO, Nevada. In Proc. Eighth Thematic Conf. on Geologic Remote Sensing (Denver), 563-571.

Sabine Chabrillat., Alexander F.H. Goetz., Lisa Krosley., Harold W. Olsen., 2002. Use of hyperspectral images in the identification and mapping of expansive clay soils and the role of spatial resolution. Remote Sensing of Environment, 82, 431445 .

Williams, G., 2009. Rattle: A Data Mining GUI for R, Graham J Williams, The R Journal, 1(2):45-55. 